\title{
Artificial intelligence application for predicting slope stability on soft ground: a comparative study
}

\author{
Mohd Badrul Hafiz Che Omar ${ }^{*}$, Rufaizal Che Mamat ${ }^{2}$, Abdul Rauf Abdul Rasam ${ }^{3}$, Azuin Ramli ${ }^{2}$ \\ and Abd Manan Samad ${ }^{4}$ \\ Scholar, in Built Environment at Faculty of Architecture, Planning and Surveying, Universiti Teknologi MARA, \\ Shah Alam Selangor, Malaysia ${ }^{1}$ \\ Senior Lecture, Department of Civil Engineering, Politeknik Ungku Omar, Ipoh, Perak, Malaysia ${ }^{2}$ \\ Senior Lecture, Faculty of Architecture, Planning and Surveying, Universiti Teknologi MARA, Shah Alam \\ Selangor, Malaysia ${ }^{3}$ \\ Professor, Faculty of Architecture, Planning and Surveying, Universiti Teknologi MARA, Shah Alam Selangor, \\ Malaysia $^{4}$
}

Received: 10-November-2020; Revised: 24-February-2021; Accepted: 25-February-2021

(C)2021 Mohd Badrul Hafiz Che Omar et al. This is an open access article distributed under the Creative Commons Attribution (CC BY) License, which permits unrestricted use, distribution, and reproduction in any medium, provided the original work is properly cited.

\begin{abstract}
This paper aimed to estimate the slope stability on soft ground by utilising Artificial Intelligence (AI) method that is widely used in the past decade for prediction purposes. The slope stability is predicted using Factor of Safety (FoS) that is generated with Limit Equilibrium Method (LEM) such as Ordinary, Bishop, Janbu and Morgenstern-Price and the total of 233 random datasets in this study. The output of the FoS is also estimated using the input parameters of height of slope $(H)$, unit weight slope aterial $(\gamma)$, angle of slope $(\theta)$, Coefficient of cohesion (c), and internal angle friction $(\phi)$ that are proceeded with Artificial Neural Networks (ANN) and Adaptive Neural Fuzzy-Logic Inference Systems (ANFIS). The final selected model of the slope stability is tested with the real data to produce a better result of the potential prediction in the accepted range of accuracy.
\end{abstract}

\section{Keywords}

Slope stability, Soft ground, Artificial intelligence method, ANN, ANFIS.

\section{Introduction}

Landslides are a phenomenon of natural disasters that frequently occur in Malaysia which can lead to threats the human an activity, property, accidents and loss of life [1]. This brought various losses to the country's economy. Based on the Risk Map and Hazard Map Study implemented by Jabatan Kerja Raya (JKR) in 2017, there were 4851 slopes along the federal lane sand highways that is categorised as high risk throughout the country. Within 2015, a total of 700 cases of landslides and slope failures have occurred [2]. In this regard, the emergence of various social, economic, technical and legal issues which has led to the need for a standard operating procedure for specific slope stability forecasts to be adopted by all authorities in the country to enable a comprehensive disaster mitigation risk management action created.

*Author for correspondence

362
In most countries, landslides are considered to be one of the worst natural disasters and cause major social and economic disadvantages [3]. From 1973 to 2007, the overall economic loss in Malaysia due to landslides was estimated at about US \$ 5 billion from JKR in 2009. Throughout 2015, a total of 700 landslides and slope failures have occurred and reported in Malaysia [4]. During the period between 1963 and 2014, Malaysia had faced many major and medium landslide disasters which caused up to 500 fatalities in total as well as substantial loss of properties, collapsed of multi-storeyed buildings, damage on roads and high-ways, and loss of environmental resources [5].

The Malaysian Cabinet meeting on 26 May 2004 decided that a study on slope master plan would be carried out. Some of the scope contained in the plan is regarding mapping, assessment and monitoring of disasters. Hence, the goal of this study is to predict 
the stability on soft ground using a few of methods that give earlier result before applying on the ground. This improvement is taking into account the universal stability factor and basic deposition. Expected results will facilitate compliance with design principles, guidelines and rules.

The results of the findings will be assessed with the result of FEM calculation. Based on the design output used as a target value, the prediction is done using the AI (Artificial Intelligence) method i.e. ANN (Artificial Neural Network) and ANFIS (Adaptive Neuro Fuzzy-Logic Inference System). Models with the best precision will be used to predict the slope stability contained in the standard operating procedures to be recommended. For this reason, this study aims to:

- To identify the application of AI that are used to get the early slope stability prediction from the data.

- To comparing between the AI application, the method which better to applying in the field with the most less risks.

\section{Literature review}

Artificial Intelligences (AI) is the sole purpose of simulating human actions, all about getting machines or computer-based robots to learn human behaviour to be able to perform tasks that human beings would naturally have participated in. AI aims to replicate machines run by computers and computers in order to be able to learn and obtain information. Once such devices and computers have to gain information, by making appropriate assumptions on current issues at hand, they should be able to think. AI approach massively to solve the complex work, save the budget and improve the service of quality [6]. This technology is one of the branches of science in making objects intelligences as human being [7]. The most important part in AI approaches is using machine learning that will make conceptual of smart machine [8] but in this study is focused on the uses of Artificial Neural Network and Adaptive Neuro Fuzzy-Logic Inference in the slope study.

\subsection{ANFIS models}

The Adaptive Neural Fuzzy-Logic Inference Systems (ANFIS) models are form by Artificial Neural Network and Fuzzy-Logic. The synthesis of these two algorithms emerges out of each isolated paradigm 's difficulties and inherent limitations. Generically, they are called Neuro-Fuzzy Structures when they are used in a mixed manner [9]. Membership Function (MF) is a function that shows the mapping of data input points into its membership value [10].

MF types and MF number can affect the ANFIS model learning process. ANFIS prediction model involves input and output parameters similar to ANN. By using input and output data sets, ANFIS builds FIS (Fuzzy Inference System) using Sugeno FIS parameters. The data set is loaded using grid partitioning method. At the input portion, the type Membership Function (MF) function together with the number of MF of three has been selected for use. The linear MF is used in the output section. Due to the requirement of the Sugeno type system which requires a single output, the ANFIS model structure used is three inputs and one output.

\subsection{ANN models}

A mathematical model created by elementary processing units, called neurons, is a neural network. Neurons are computational units which are strongly interconnected. Artificial neural networks (ANNs) are known to be information processing systems capable of learning, remembering and generalizing data from training [11]. It can prove the most effective solution of complex problem based on conventional computation method [12]. Too many neurons in invisible layers interfere with the potential of the network and create overtraining conditions for the network. It is difficult to classify the number of neurons in invisible layers.

There is no systematic or statistical method for maximising the number of neurons. After attempting various network configurations, the number of neurons in the hidden layer can be obtained since no theory can still be used to calculate the number of neurons in the hidden layers. The number of neurons in secret layers is normally calculated by the test process. The trained ANN usually produce a good input and output based on its target [13].

\subsection{Concept of slope stability analysis}

Slope stability is assessed by calculating and assessing the stability index called factor of safety (FoS). This FoS is defined as the ratio of ground resistance forces along the surface failure to the power of instability [14]. When FoS exceeds the value of 1 , this indicates the slope is stable, if the FoS is equals 1 means the slope is at the equilibrium limit. Using the formula mobilized shear strength (rf) and available strength ( $\mathrm{r}$ ). If the mobilized strength less than available strength, the slope will be stable. However, most of the FoS formula used is derived 
from the Mohr-Coulomb failure criterion which predicts the shear strength of unsaturated soil [15].

Basically there are two approaches in analyzing slope stability i.e. determination and probability or reliability [16]. Traditional or conventional methods commonly used for slope stability analysis are Limit Equilibrium Method (LEM), where a safety factor value is calculated to predict slope stability on soft ground. Thereafter, some researchers have developed Finite Elements Method (FEM) as a technique in analyzing slope stability problems. In short, these two methods have advantages and disadvantages. In this study four methods used to measure the safety factor Morgenstern-price, janbu, ordinary and Bishop were applied.

Factor of safety $=\frac{\text { Shear strength }}{\text { strength }}$

\section{Material and method}

The key data used in this analysis comes from field observation and monitoring. The selected panorama selected equipped at the indicated location with horizontal and vertical pressure cells, inclined feet, vertical and pneumatic pipe piezometers and surface submersible markers as shown in Figure 1 . The incline metres in the boreholes are used to recognise the ability of the movement of the slope plane [17, 18]. Monitoring on the field for 185 days after the construction has been conducted and the data collected by these instruments an inclined measurement device consisting of detectors, control cables, pulleys and readings are used to measure horizontal deflection over the whole slope. A box behind the wall is positioned and every $0.5 \mathrm{~m}$ pitch is measured by inserting the detector into the box. The vertical and horizontal ground pressure with effective stresses and pore pressure is measured with a pair of total pressure cells and the performance is measured by using a pneumatic piezometer on the slope foundation.

Figure 2 shows the main methods used in the study. The collection of data input is first step of the study where the data were sorted into good and decreased data with unspecific tolerances. All data must be processed early to obtain ready data for Factor of Safety (FoS).

The data are placed in Slope W software to generate FoS results. It was very important because if the data did not include the correct and reliable FoS, the prediction with Slope stability was difficult to obtain. Data from FoS are applied to the MatLab with the ANN and ANFIS methods provided by MatLab ToolBoxs. To obtain the successful result, the tolerance must be closest to 1.0. If the result is more than 1.0, the data cannot be used on the ground. It supports Root Mean Square Error (RMSE) from results. Finally, comparative study of RMSE and R2 are also conducted.

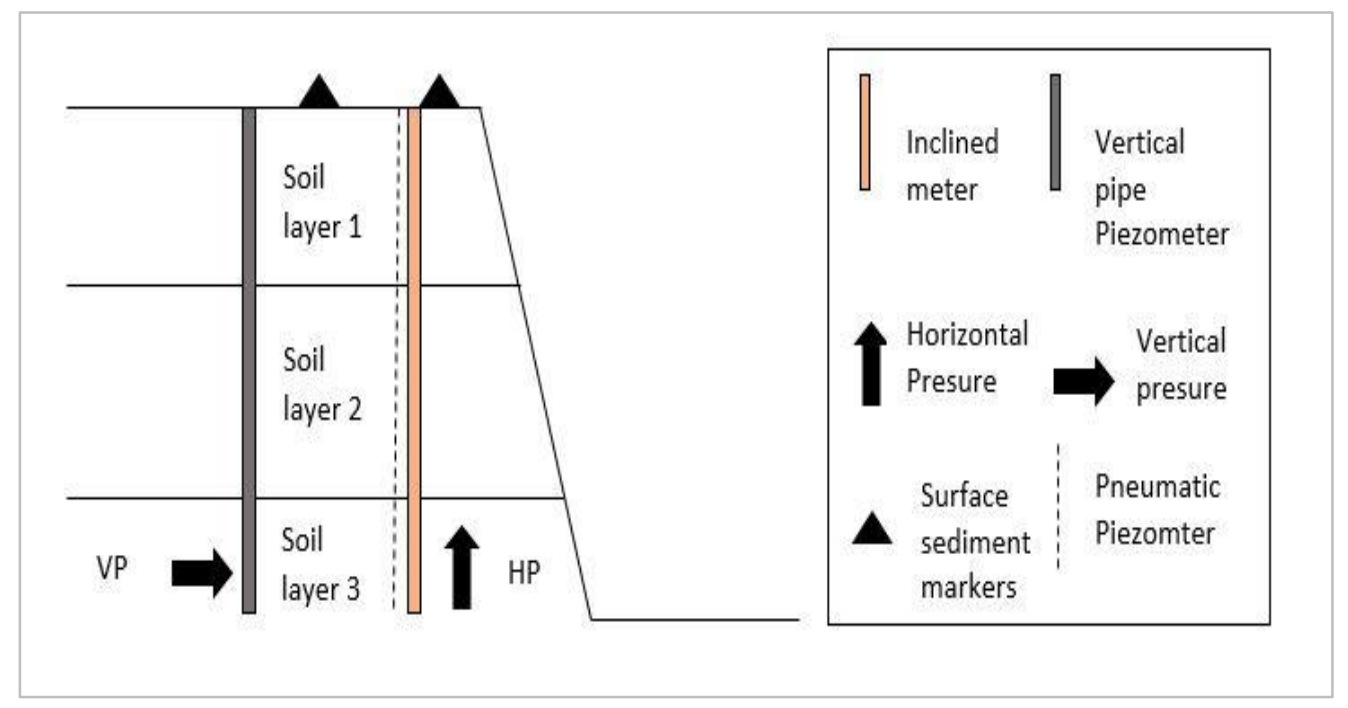

Figure 1 Installation of instruments in the field 

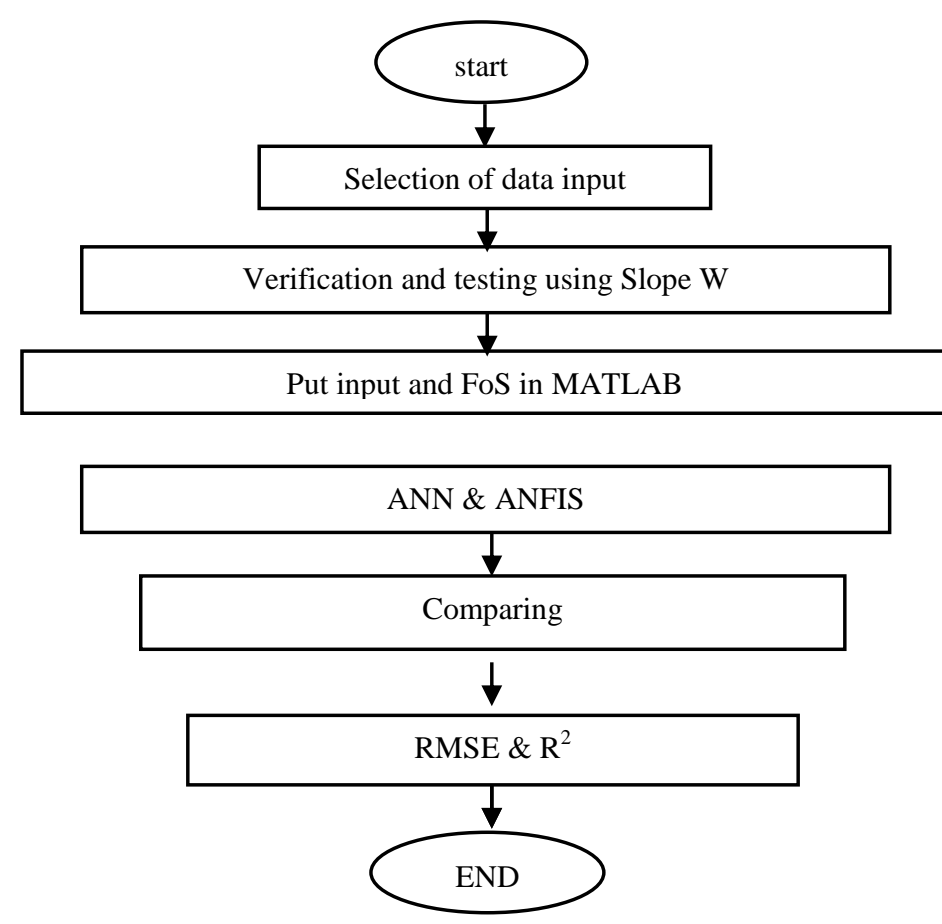

Figure 2 Flowchart prediction of Slope Stability

\section{Result and discussion}

The result from processing data in slope/W is 3.280 for Morgenstern-Price, 3.240 for Ordinary, 3.286 for Bishop, and 3.198 for Janbu. Figure 3, 4, 5, 6 until 6 show the result for Factor of Safety (Fos). From the result of Slope W, ordinary method is chosen because this method is very close to the 3.30 and bring for

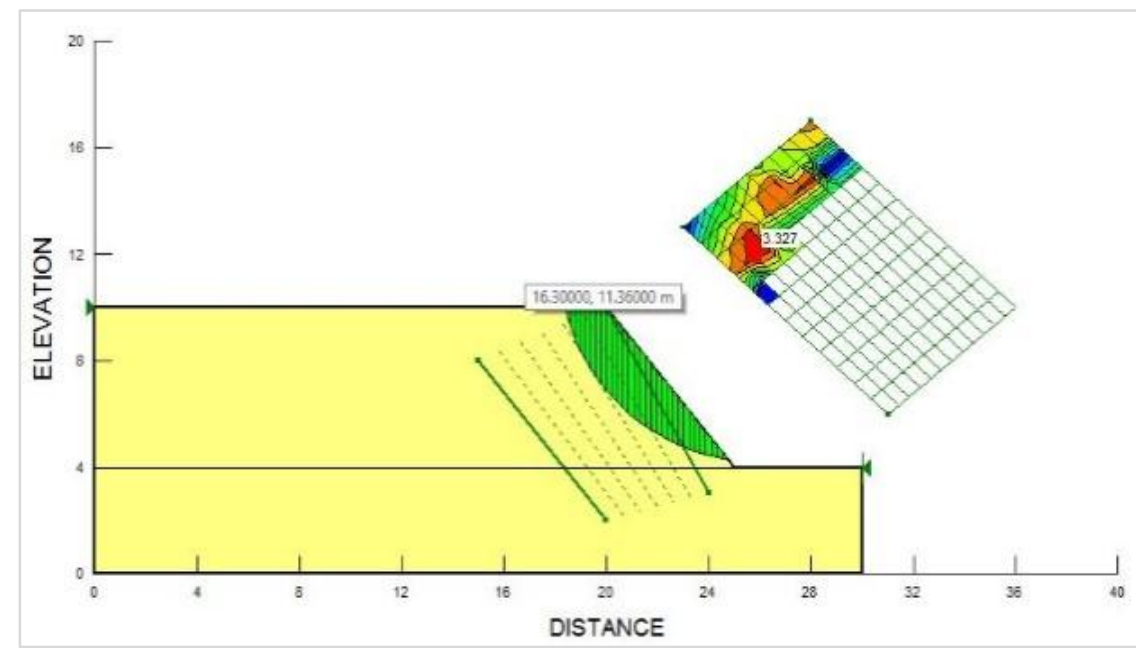

Figure 3 Factor of safety Morgenstern-Price
ANN and ANFIS to get the better result. The 233 datasets are divided into 3 parts namely, $x 1, x 2$, and $\mathrm{x} 3$ for comparative study of the accuracy of the techniques. Table 1 shows the example of data and the ANN Result. 
Mohd Badrul Hafiz Che Omar et al.

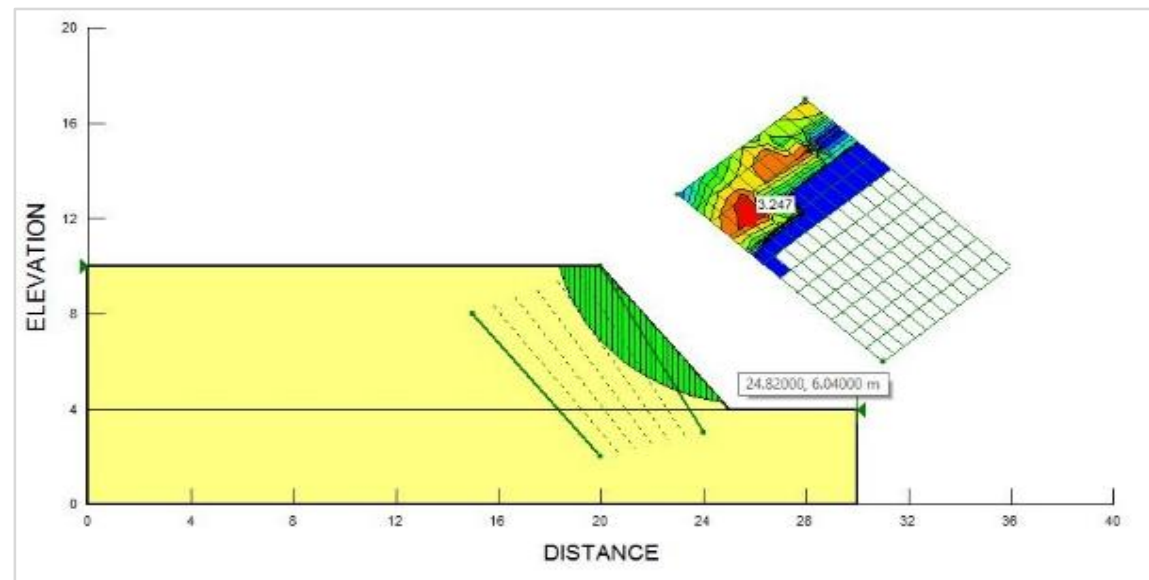

Figure 4 Factor of safety ordinary

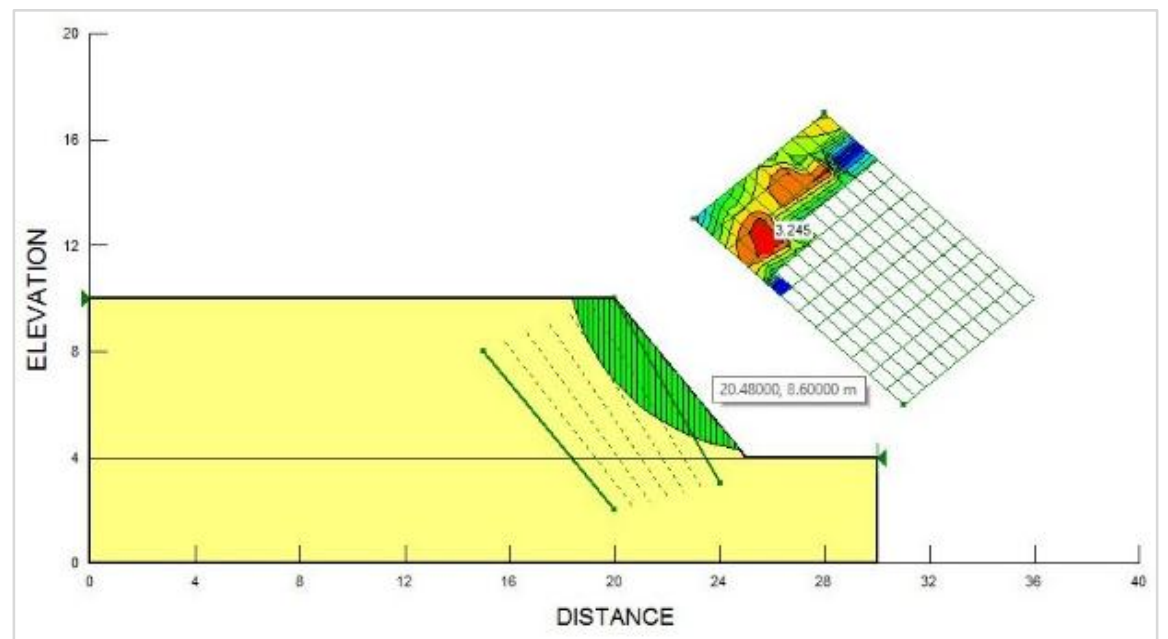

Figure 5 Factor of safety Janbu

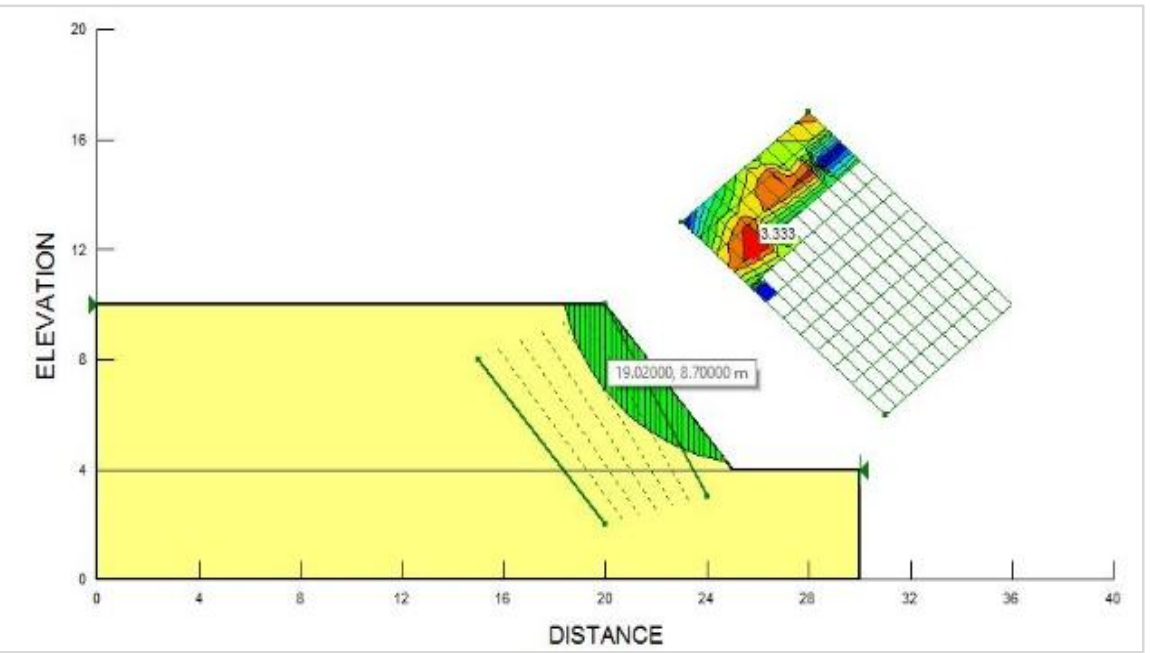

Figure 6 Factor of safety Bishop 
Table 1 The half partial dataset input with target

\begin{tabular}{cccc}
\hline $\mathrm{X} 1$ & $\mathrm{X} 2$ & $\mathrm{X} 3$ & Target /ordinary \\
\hline 0 & 0 & 1.425 & 3.286 \\
\hline 1 & 5 & 2.475 & 3.286 \\
\hline 1 & 10 & 3.375 & 3.286 \\
\hline 2 & 15 & 4.575 & 3.286 \\
\hline
\end{tabular}

The data is put in the neural network fitting in the MatLab R2015a and using Levenberg-Marquardt method in MatLab tool. Levenberg-Marquardt is one of the methods that used to solve non-linear least square problems and it was a part in ANN method. It was default method that give from MatLab.

Figure 7 shows the main flowchart used for ANN input datasets and output. Using 3 divide dataset and choosing 10-layer hidden neuron. Lastly the result in output is produced. From the random dataset, they are divided into three kind of samples, training, validation, and testing. For training, $70 \%$ of the data are taken in which mean 163 samples, validation $15 \%$ 35 sample and testing $15 \%$ for 35 sample.
Figure 8 show the result from ANN and Figure 9 and Figure 10 show the ANFIS model structure with the rules.

From the Table 2, this RMSE and $\mathrm{R}^{2}$ are used to compare with ANFIS method. The result is load into Neural Fuzzy-logic designer by MatLab R2015a. Number of training data pair 233 with 27 rules and 27 output Membership Function (MF). From the output MF are produced output that contains Training, Validation and Testing. The result will show below

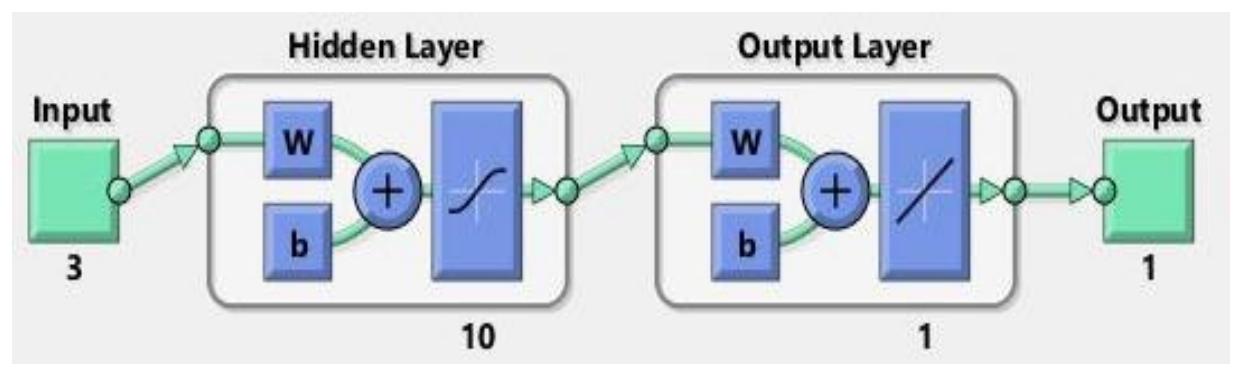

Figure 7 The flowchart ANN input and output
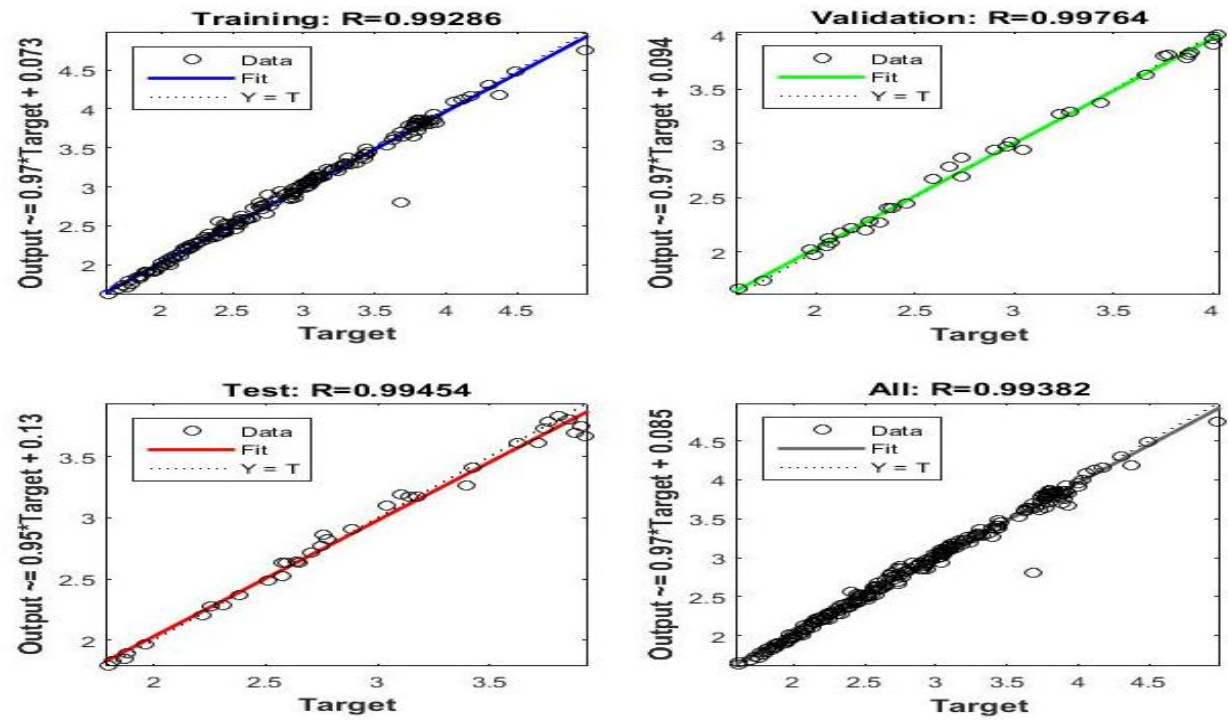

Figure 8 The output result from ANN 
Mohd Badrul Hafiz Che Omar et al.

Table 2 The result for ANN

\begin{tabular}{cccc}
\hline & Data & RMSE & $\mathbf{R}^{\mathbf{2}}$ \\
\hline Training & 163 & 0.00369680 & 0.99286 \\
\hline Validation & 35 & 0.00305153 & 0.99764 \\
\hline Testing & 35 & 0.00387300 & 0.99454 \\
\hline
\end{tabular}

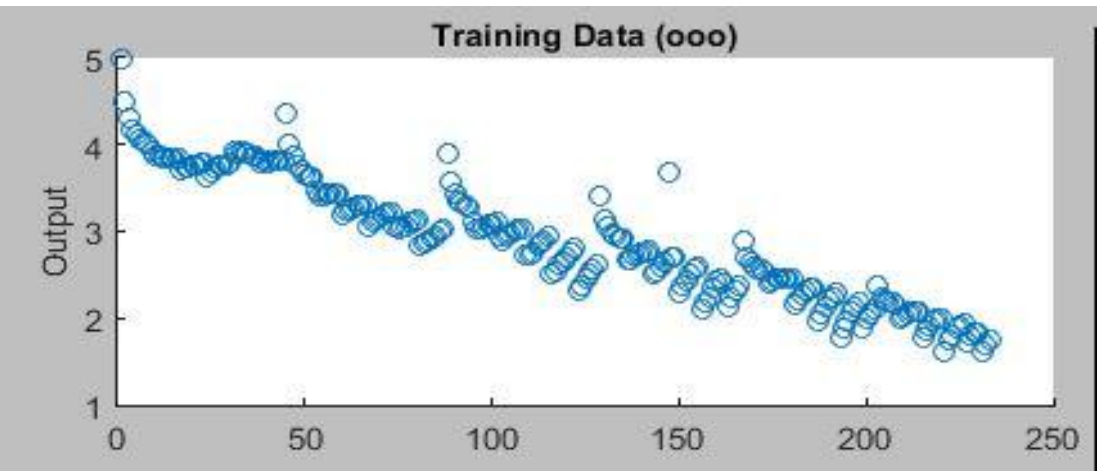

Figure 9 The result output from ANFIS rules

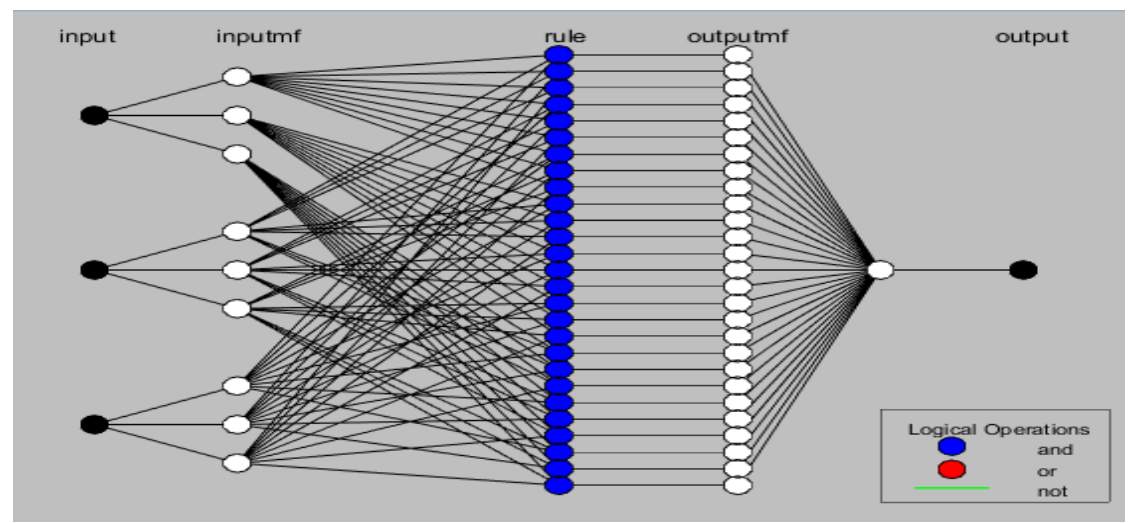

Figure 10 ANFIS model structure with the rules

Comparing RMSE and $\mathrm{R}^{2} \mathrm{ANN}$ and ANFIS from the output that have been produced from the both of processing, can be concluded that ANFIS Rules RMSE and $\mathrm{R}^{2}$ more accurate compared to ANN Rules. The tolerance must be achieved nearest to 1.0. that can be observe from the result for Training sample data between ANN and ANFIS which is 0.00369680 and 0.00368673 for RMS. While for $\mathrm{R}^{2}$ is 0.99286 and 0.99937 .

\section{Conclusion and future work}

This study is conducted to forecast the slope stability on soft ground by using artificial intelligence (AI) method and 5 parameters: slope height, unit weight slope content, slope angle and inner angle friction Coefficient of cohesion. Although the study is also tested with the use of Limit Equilibrium Method (LEM) method, the AI technique of Adaptive Neuro Fuzzy Inference (ANFIS) approach was still finally selected to predict the stability model. The finding has shown that ANFIS could predict a high precision safety factor compared to others including the Artificial Neural Network technique. ANFIS predict show the safety factor with the higher accuracy and nearest to the targeted accuracy [19]. In the future, the other techniques could be explored such as Support Vector Machines (SVM) towards determining the significant prediction on the slope stability measurement.

\section{Acknowledgment}

This project was funded by a Fundamental Research Grant Scheme [Ref: FRGS / 1/2018 / TK06 / UITM / 01/1] in Universiti Teknologi MARA (UiTM). The cooperation of UiTM Research Management Centre (UiTM-RMC) in this project is also appreciated.

\section{Conflicts of interest}

The authors have no conflicts of interest to declare. 


\section{References}

[1] Zaki A, Chai HK, Razak HA, Shiotani T. Monitoring and evaluating the stability of soil slopes: a review on various available methods and feasibility of acoustic emission technique. Comptes Rendus Geoscience. 2014; 346(9-10):223-32.

[2] https://www.bharian.com.my/berita/nasional/2015/12/ 107122/700-kes-tanah-runtuh-sepanjang-tahunrosnah. Accessed 08 November 2020.

[3] Feng Z, Wu C, Zhu Z, Xia Y, Wang Y. Theoretical approach of soil slope slip monitoring based on composite optical fiber devices. Journal of Nanoelectronics and Optoelectronics. 2017; 12(11):1274-9.

[4] Hussin H, Ghani SA, Jamaluddin TA, Razab MK. Tanah runtuh di Malaysia:'Geobencana'atau 'Geobahaya,”, J. Teknol.. 2015; 77(1):229-35.

[5] Rahman HA, Mapjabil J. Landslides disaster in Malaysia: an overview. Health. 2017; 8(1):58-71.

[6] Mamat RC, Kasa A, Razali SF, Samad AM, Ramli A, Yazid MR. Application of artificial intelligence in predicting ground settlement on earth slope. In AIP conference proceedings 2019 (p. 040015). AIP Publishing LLC.

[7] Mamat RC, Kasa A, Razali SF, Ramli A, Omar MB. Slope stability prediction of road embankment on soft ground treated with prefabricated vertical drains using artificial neural network. IAES International Journal of Artificial Intelligence. 2020; 9(2):236-43.

[8] Mamat RC, Kasa A, Razali SF. The applications and future perspectives of adaptive neuro-fuzzy inference system in road embankment stability. Journal of Engineering Science \& Technology Review. 2019; 12(5):75-90.

[9] Vieira J, Dias FM, Mota A. Neuro-fuzzy systems: a survey. In 5th WSEAS NNA international conference on neural networks and applications, Udine, Italia 2004 (pp. 87-92).

[10] Rahman Z. Slope stability analysis and road safety evaluation. Lulea University of Technology, Lulea, Sweden. Thesis. 2012.

[11] Attoh-Okine NO. Combining use of rough set and artificial neural networks in doweled-pavementperformance modeling - a hybrid approach. Journal of Transportation Engineering. 2002; 128(3):270-5.

[12] Barhmi S, El Fatni O. Hourly wind speed forecasting based on support vector machine and artificial neural networks. IAES International Journal of Artificial Intelligence. 2019; 8(3):286-91.

[13] Mai SH, Seghier ME, Nguyen PL, Jafari-Asl J, Thai DK. A hybrid model for predicting the axial compression capacity of square concrete-filled steel tubular columns. Engineering with Computers. 2020:1-8.
[14] Zhao L, Yang F, Zhang Y, Dan H, Liu W. Effects of shear strength reduction strategies on safety factor of homogeneous slope based on a general nonlinear failure criterion. Computers and geotechnics. 2015; 63:215-28.

[15] Zou C, Wang Y, Lin J, Chen Y. Creep behaviors and constitutive model for high density polyethylene geogrid and its application to reinforced soil retaining wall on soft soil foundation. Construction and Building Materials. 2016; 114:763-71.

[16] Kaur A, Sharma RK. Slope stability analysis techniques: a review. International Journal of Engineering Applied Sciences and Technology. 2016; 1(4):52-7.

[17] Chen T, Deng J, Sitar N, Zheng J, Liu T, Liu A, Zheng L. Stability investigation and stabilization of a heavily fractured and loosened rock slope during construction of a strategic hydropower station in China. Engineering Geology. 2017; 221:70-81.

[18] Erzin Y, Cetin T. The use of neural networks for the prediction of the critical factor of safety of an artificial slope subjected to earthquake forces. Scientia Iranica. 2012; 19(2):188-94.

[19] Mohamed T, Kasa A, Taha MR. Fuzzy logic system for slope stability prediction. Journal of Nanoelectronics and Optoelectronics. 2012; 12(11):38-42.

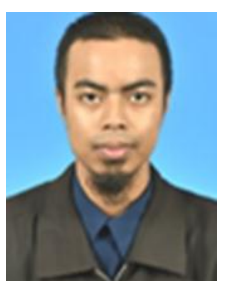

Mohd Badrul Hafiz Che Omar, received a Bachelor Degree in Surveying and Geomatics in 2016 from Universiti Teknologi Mara (UiTM) Shah Alam, Selangor, Malaysia. Master in Sciences Geographical Information Systems in 2018 at same University. Now, he is a research assistant and is currently studying for a Ph.D. also at the same University and currently conducting a research project in slope stability for an embankment on soft ground.

Email: md.badru192@gmail.com

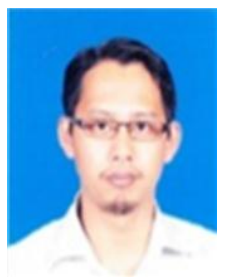

Rufaizal Che Mamat is a senior lecturer at Politeknik Ungku Omar and has served for 17 years. He began his undergraduate studies in 1998 at Universiti Teknologi Tun Hussien Onn, Malaysia. He is currently pursuing his Ph.D. at Universiti Kebangsaan Malaysia (UKM) in Geotechnical

Engineering.

Email: rufaizal.cm@gmail.com 


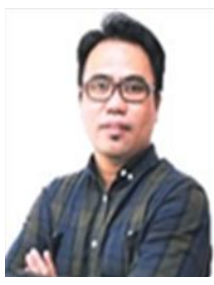

Abdul Rauf Abdul Rasam is a senior lecturer and researcher in the Faculty of Architecture, Planning and Surveying, Universiti Teknologi MARA (UiTM) Shah Alam, Selangor, Malaysia. He obtained his $\mathrm{PhD}$ from Universiti Sains Malaysia (USM) in GIS (Geospatial Modelling and Geovisualisation). He has published a number of indexed papers in various topics on geospatial and geomatics such as GIS, Cartography, Mapping, Remote Sensing and related fields of computer sciences, social, health and environmental studies. In addition, he has received innovation awards from national and international organizations. Currently, his team is developing a new generation model of Infectious Disease using Geospatial Big Data Analytics.

Email:rauf@uitm.edu.my

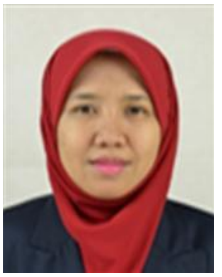

Azuin Ramli is a senior lecturer in civil engineering at Politeknik Ungku Omar (PUO). She received his doctorate from UTHM in 2015 in building construction. She has published over 12 articles in various fields of Civil Engineering.

Email: azuinramli@gmail.com

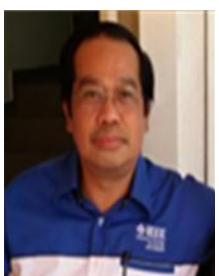

Abd Manan Samad is a Professor at the Faculty of Architecture, Planning \& Surveying, Universiti Teknologi MARA (UiTM). He has served over 30 years in the education system. He has extensive experience in Land Survey Engineering research and has published over 350 papers.

Email: dr_abdmanansamad@ieee.org 